\title{
Addition of Risk Factors of Coronary Heart Disease in Diagnostic Value of Treadmill Score for Detecting Complexity of Coronary Arterial
}

\author{
Mariyetty K.S. Nasution ${ }^{\star 1}$, Abdullah A. Siegar ${ }^{1}$, Harris Hasan ${ }^{1}$, \\ Zulfikri Mukhtar ${ }^{1}$, Abdul H. Raynaldo ${ }^{1}$, Nizam Akbar ${ }^{1}$ \\ 'Department of Cardiology and Vascular Medicine, University of Sumatera Utara, \\ Adam Malik Hospital, Medan, Indonesia
}

\begin{abstract}
Background : Coronary heart disease (CHD) is still the leading cause of death in the world. There are various risk factors for atherosclerosis leading to CHD. Duke Treadmill Score (DTS) is known to demonstrate prognostic stratification and has a diagnostic value in predicting the number of coronary arteries involved in patient populations with ischemic heart disease. However, DTS does not describe the role of risk factors for coronary heart disease to the complexity of coronary artery lesions. This study aims to add risk factors for coronary heart disease on DTS to detect the complexity of coronary artery lesions with stable angina pectoris. Methods : This study was cross-sectional study in stable angina pectoris patient who come to Haji Adam Malik Hospital Medan since January 2017 until February 2018. Patients who have done treadmill test and coronary angiography, and fulfill inclusion and exclusion criteria are included in the study. ECG examination and recording of risk factors for coronary heart disease were done. DTS assessment was performed based on treadmill test and Syntax score based on coronary angiography results. Diagnostic tests were performed to assess the sensitivity and specificity of the addition of CHD risk factors to detect the complexity of coronary artery lesions.
\end{abstract}

Results : Of the 76 people with stable angina pectoris, 55 people were found with low SYNTAX and 21 people with high Syntax. DTS is divided into 3 groups: mild (> -10), moderate (-10 to -13.5), and severe ( $\leq-13.6)$ based on the cut off of the ROC curve. Risk factors for CHD are divided into 3 groups, mild $(\leq 3)$, moderate (4-6), and severe (7) based on the cut off of the ROC curve too, then assessed the relationship with SYNTAX which has been divided into 2 groups, low Syntax and high Syntax. Diagnostic test show the addition of risk factors of CHD to DTS to detect the complexity of coronary artery lesions have greater sensitivity and specificity than DTS without the addition of risk factors of CHD, 95\% and $89 \%$.

Conclusion : The addition of risk factors for coronary heart disease on DTS can detect the complexity of coronary artery lesions.

Keywords : Duke Treadmill Score, risk factors for Coronary Heart Disease, Complexity of Coronary Artery Lesions, Syntax. 


\section{Introduction}

Coronary heart disease (CHD) is a condition where there is an imbalance between oxygen supply and the needs that cause hypoxic conditions in the myocardium and accumulation of metabolic waste substances that are generally caused by the process of atherosclerosis in the coronary arteries ${ }^{1}$. CHD is the leading cause of death in the world. A report from the World Health Organization (WHO) in 2013, 17.5 million people dies each year from cardiovascular disease, about $31 \%$ of the total deaths worldwide ${ }^{2}$.There are various risk factors for atherosclerosis that encourage CHD, both modifiable risk factors such as diabetes mellitus, hypertension, smoking, lack of activity and dyslipidemia, or those that cannot be modified such as age, sex, and family history $^{3}$. The most common clinical presentation of CHD is stable angina pectoris followed by acute coronary syndrome and then sudden death. Treadmill Training Test (ULT) is the most widely used test to conduct an initial evaluation of patients with angina pectoris ${ }^{4}$. Prognostic value of ULT based on exercise duration, ST segment deviation (depression or elevation), and the presence and severity of angina that arises during exercise. This value is known as Duke Treadmill Score (DTS) which shows prognostic stratification in a population of patients with a history of miocard infarction and with typical chest pain ${ }^{5,6}$.

There are several value systems used to describe the complexity of coronary artery lesions. The commonly used value system is Syntax (SYnergy between percutaneous coronary intervention with TAXus and cardiac surgery). Syntax can objectively determine the upper limit of suitability for revascularization with percutaneous intervention methods or revascularization methods with coronary bypass surgery ${ }^{7}$. Duke Treadmill Score has been shown to have a strong correlation with the complexity of coronary artery lesions assessed by Syntax ${ }^{8,9}$. However, DTS does not describe the role of risk factors for coronary heart disease in the complexity of coronary artery lesions, there is no data regarding the addition of risk factors for CHD in DTS diagnostic values in predicting the complexity of coronary artery lesions assessed based on Syntax.

\section{Methods}

This study is a diagnostic study with cross-sectional design. This study uses Treadmill test data, history of risk factors for coronary heart disease, and coronary angiography at RSHAM from January 2017 to February 2018. Patients who present with stable angina pectoris CCS II-III and sinus rhythm, can perform treadmill test and no contraindication to treadmill testand coronary angiography is included in the study. Patients who cannot perform treadmill test, refuse to do coronary angiography, chronic kidney disease, a history of severe valvular disease, congenital heart disease, heart failure, acute coronary syndrome, coronary heart disease, myocardial infarction, or previously revascularization is excluded in research. The independent variable in this study is DTS and CHD risk factors including Diabetes Mellitus, hypertension, dyslipidemia, BMI, smoking, gender, and age. CHD risk factors will be divided into mild risk factors $(\leq 3$ CHD risk factors), moderate (4-6 CHD risk factors), severe (7 CHD risk factors) based on the Receiver Operating Characteristic (ROC) cutoff point. The dependent variable in this study is the complexity of coronary artery lesions which are assessed by Syntax I score which is then divided into low Syntax values $(\leq 22)$ and high Syntax $(>22)$.

Treadmill test in this study used Bruce protocol. DTS is obtained based on the calculation of exercise duration (in minutes) - 5x (deepest ST segment deviation in $\mathrm{mm}$ ) $-4 \mathrm{x}$ (angina score) ${ }^{10}$. The duration of the exercise used in the calculation is based on the duration of the exercise in minutes on the Bruce protocol.

\section{Statistical Analysis}

Statistical data processing and analysis using statistical computer devices. Categorical variables are presented with the number or frequency (n) and percentage (\%). Numerical variables are presented with mean values with standard deviations for data that are normally distributed. Test the normality of numerical variables in all study subjects using the Kolmogorov-Smirnov test with $n>50$. Comparison between the two groups in categorical independent variables and categorical dependent variables using Chi-Square test ( Fisher test).Comparison between the two groups on numerical independent variables and category dependent variables is done by independent $\mathrm{T}$ test ( Mann Whitney test). We used receiver operating characteristic analysis todetermine the optimal cut off point of DTS. UsingChi-squared table, we obtained sensitivity, specificity, positive predictive value (PPV) and negative value (NPV). The association of the DTS test results on the complexity of coronary artery lesions will be compared with the association of the DTS test results with additional risk factors for CHD in the form of sensitivity and specificity ${ }^{11}$. All statistical analyses were performed using SPSS, version 22.0 and $p$ value $<0,05$ was considered as statistically significant 


\section{Results}

This study took place from January 2017 to February 2018 at Haji Adam Malik Hospital Medan. The total number of study who met the inclusion and exclusion criteria were 76 subjects consisting of 21 people with high Syntax and 55 people with low Syntax. Male gender consisted of 19 people $(90.5 \%)$ in the group with high Syntax and 37 people (67.3\%) in the low Syntax. The average age of 54.43 years was in the group with high Syntax and 53.36 years in the low Syntax. After that, a bivariate analysis was carried out on the factors that influenced Syntax in both groups. In bivariate analysis, CHD risk factors such as hypertension, dyslipidemia, BMI, sex, age, and diabetes melitus did not have a significant difference between groups with high Syntax and low Syntax. In addition, there were no significant differences between treatment history, and laboratory values such as $\mathrm{HbA1C}$, fasting blood glucose, add random blood glucose, 2 hours postprandial blood glucose, HDL, LDL and triglycerides. CHD risk factors that is dyslipidemia and mean DTS have statistically significant differences in the two groups of Syntax . In the group of subjects with high Syntax there were 15 (71.4\%) subjects with dyslipidemia and $21(38.2 \%)$ subjects with dyslipidemia at low Syntax $(p=0.011)$. The mean DTS in the high Syntax group was $-18.63 \pm 8.85$ and the low Syntax was $-9.21 \pm 3.41(\mathrm{p}=0.000)$ (Table.1). Syntax assessment was carried out by two cardiologist consultants who first performed the kappa interoberver test to find the suitability of the interpretation. From the kappa test, it was obtained a value of 0.773 with $\mathrm{p}<0.001$, meaning that there was a good match between the first and second observations.

Table 1. Demographic and clinical characteristics based on Syntax

\begin{tabular}{|c|c|c|c|}
\hline & $\begin{array}{l}\text { SYNTAX High } \\
(\mathrm{n}=21)\end{array}$ & $\begin{array}{l}\text { SYNTAX Low } \\
(n=55)\end{array}$ & P value \\
\hline $\begin{array}{l}\text { Gender } \\
\text { Male n }(\%) \\
\text { Female n }(\%)\end{array}$ & $\begin{array}{l}19(90,5) \\
2(9,5)\end{array}$ & $\begin{array}{l}37(67,3) \\
18(32,7)\end{array}$ & $0,040^{\mathrm{a}}$ \\
\hline Age(Average \pm SD), Year & $54,43 \pm 6,80$ & $53,36 \pm 8,15$ & $0,567 \mathrm{~b}$ \\
\hline Heart Rate(Average \pm SD), $\mathrm{x} /$ minute & $80,19 \pm 8,98$ & $78,36 \pm 8,59$ & $0,428 \mathrm{~b}$ \\
\hline TDD(Average \pm SD), $\mathrm{mmHg}$ & $82,38 \pm 13,00$ & $85,09 \pm 11,99$ & $0,392 b$ \\
\hline TDS (Average $\pm \mathrm{SD}), \mathrm{mmHg}$ & $134,76 \pm 10,30$ & $138,51 \pm 13,05$ & $0,241 \mathrm{~b}$ \\
\hline $\mathrm{BMI}($ Average $\pm \mathrm{SD}), \mathrm{kg} / \mathrm{m} 2$ & $25,09 \pm 2,70$ & $26,13 \pm 3,38$ & $0,172 b$ \\
\hline $\begin{array}{l}\text { Risk Factor PJK } \\
\text { Diabetes Mellitus, n (\%) } \\
\text { Hypertension, n (\%) } \\
\text { Smoke, n (\%) } \\
\text { Dislipidemia, n (\%) } \\
\text { Age, n }(\%)\end{array}$ & $\begin{array}{l}8(38,1) \\
16(76,2) \\
17(81) \\
13(61,9) \\
18(85,7)\end{array}$ & $\begin{array}{l}15(27,3) \\
45(81,8) \\
35(63,6) \\
18(32,7) \\
44(80)\end{array}$ & $\begin{array}{l}0,358 \mathrm{a} \\
0,581 \mathrm{a} \\
0,043 \mathrm{a} \\
0,021 \mathrm{a} \\
0,745 \mathrm{a}\end{array}$ \\
\hline Long Diabetes Mellitus & $1,48 \pm 3,07$ & $1,04 \pm 2,30$ & $0,557 \mathrm{~b}$ \\
\hline Duke Treadmill Score & $-19,95 \pm 8,28$ & $-10,56 \pm 4,60$ & $0,000 \mathrm{~b}$ \\
\hline $\begin{array}{l}\text { Laboratory } \\
\text { HbA1C (Average } \pm \mathrm{SD}), \% \\
\text { GDP (Average } \pm \mathrm{SD}), \mathrm{mg} / \mathrm{dL} \\
\text { GDS (Average } \pm \mathrm{SD}), \mathrm{mg} / \mathrm{dL} \\
\text { GD2jamPP (Average } \pm \mathrm{SD}), \mathrm{mg} / \mathrm{dL} \\
\text { Triglyceride }(\text { Average } \pm \mathrm{SD}), \mathrm{mg} / \mathrm{dL} \\
\text { Cholesterol total }(\text { Average } \pm \mathrm{SD}), \mathrm{mg} / \mathrm{dL} \\
\text { HDL(Average } \pm \mathrm{SD}), \mathrm{mg} / \mathrm{dL} \\
\text { LDL(Average } \pm \mathrm{SD}), \mathrm{mg} / \mathrm{dL}\end{array}$ & $\begin{array}{l}7,28 \pm 1,74 \\
133,85 \pm 44,19 \\
162,42 \pm 116,4 \\
181,90 \pm 67,8 \\
135,66 \pm 48,55 \\
188,23 \pm 50,19 \\
40,85 \pm 10,01 \\
126,57 \pm 51,04\end{array}$ & $\begin{array}{l}7,30 \pm 6,52 \\
114,72 \pm 26,64 \\
122,72 \pm 49,36 \\
180,12 \pm 58,11 \\
134,40 \pm 47,6 \\
182,12 \pm 38,72 \\
44,54 \pm 8,11 \\
117,76 \pm 33,90\end{array}$ & $\begin{array}{l}0,992 b \\
0,075 b \\
0,145 b \\
0,916 b \\
0,918 b \\
0,618 b \\
0,141 b \\
0,385 b\end{array}$ \\
\hline $\begin{array}{l}\text { Medical History }(\mathrm{n}, \%) \\
\text { Diuretics,n }(\%) \\
\text { ACE/ARB, } \mathrm{n}(\%) \\
\text { Nitrate, } \mathrm{n}(\%)\end{array}$ & $\begin{array}{l}1(4,8) \\
15(71,4) \\
19(90,5)\end{array}$ & $\begin{array}{l}1(1,8) \\
45(81,8) \\
46(83,6)\end{array}$ & $\begin{array}{l}0,479^{\mathrm{a}} \\
0,320^{\mathrm{a}} \\
0,449^{\mathrm{a}}\end{array}$ \\
\hline
\end{tabular}


Analysis with the ROC curve is done to find out the diagnostic value of DTS to predict high syntax. The area under the curve (AUC) was $90.1 \%$ (IK 0.804-0.999, $\mathrm{p}=0.000$ ) (figure 1). After that, the determination of the DTS is based on the ROC curve. The limit value is determined based on the point of intersection between the optimal sensitivity and specificity to obtain high Syntax . DTS-13.6 is considered to have optimal diagnostic value because it is considered to have a balanced sensitivity and specificity. There were 17 people with DTS $\leq$ 13.6 having high Syntax , while 44 people with DTS $\leq-13.6$ with low Syntax. Calculation of the diagnostic value is done based on a Chi-squared table and obtained a sensitivity of $90 \%$, specificity of $61 \%$, negative predictive value of $91.6 \%$ and positive predictive value of $60 \%$. DTS is then divided into 3 groups, mild (> $10)$, moderate (-10 to -13.5$)$ and severe ( $\leq-13.6)$ based on the intersection of the ROC curve.

Further analysis was carried out to determine the diagnostic value of DTS with additional risk factors for CHD to detect the complexity of coronary artery lesions. DTS with additional risk factors for CHD is divided into 2 groups, The low risk which is classifiedas mild DTS accompanied by mild, moderate or severe CHD risk factors, and the high risk which is classified as moderate or severe DTS accompanied by mild, moderate or severe CHD risk factors . Thus obtained 20 people with high risk have a high Syntax, while 49 people with low risk have a low Syntax. The calculation of diagnostic values was carried out based on Chisquare table and obtained a sensitivity of $95 \%$, specificity of $89 \%$, negative predictive value of $98 \%$, and positive predictive value of $77 \%(\mathrm{p}<0.001)($ table 2$)$

Table 2. Chi-squared table based on DTS with aditional risk factors for CHD

\begin{tabular}{|l|l|l|l|l|l|l|l|l|}
\hline $\begin{array}{l}\text { DTS with } \\
\text { additional } \\
\text { risk factors } \\
\text { for CHD }\end{array}$ & $\begin{array}{l}\text { High } \\
\text { Syntax }\end{array}$ & Low Syntax & Total & Sens & Spes & NPV & PPV & P value \\
\hline High Risk & 20 & 6 & 26 & $95 \%$ & $89 \%$ & $98 \%$ & $77 \%$ & $0,000 *$ \\
\hline Low Risk & 1 & 49 & 50 & & & & & \\
\hline Total & 21 & 55 & 76 & & \\
\hline
\end{tabular}

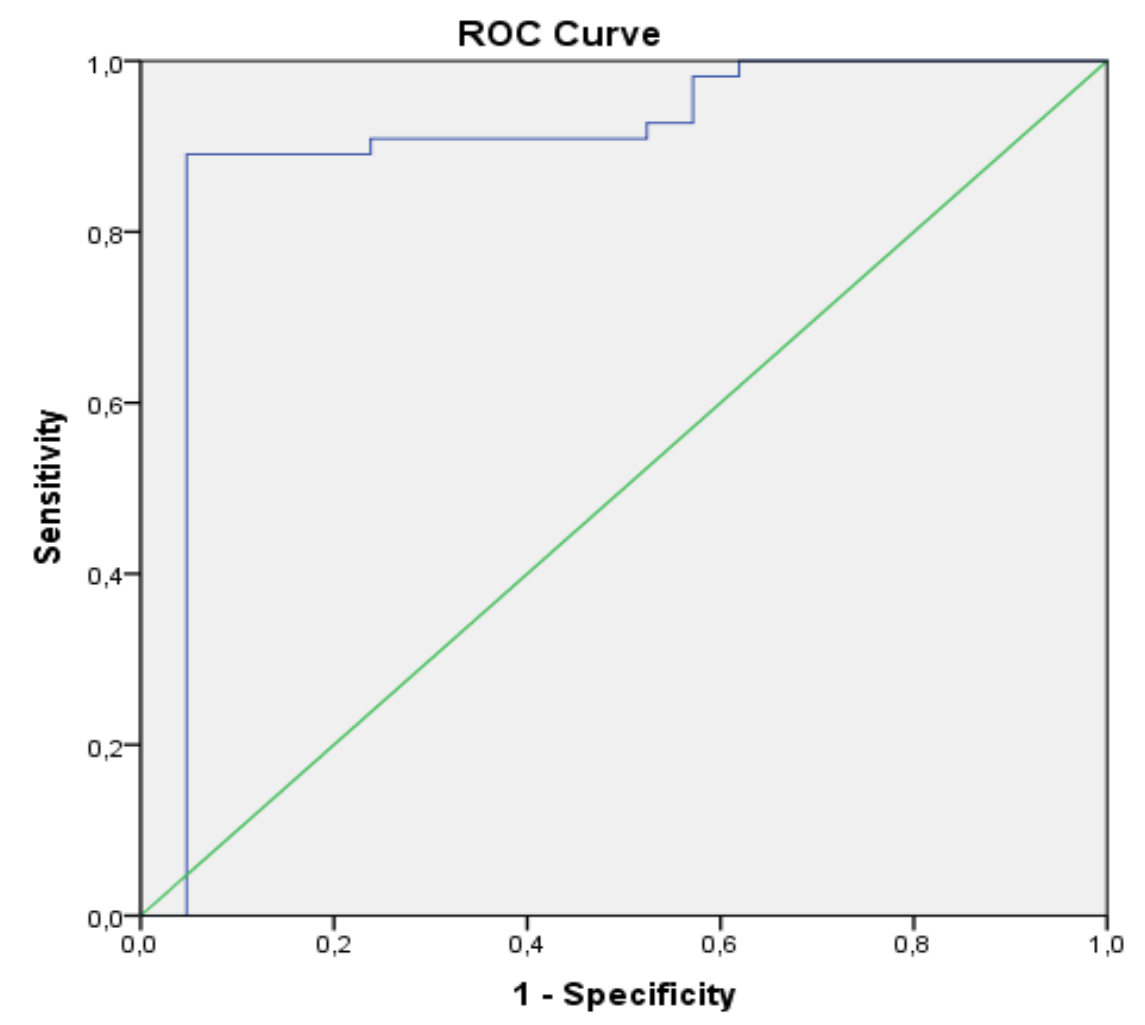

Figure 1. ROC curve of DTS to assess Syntax 


\section{Discussion}

Of the total subjects in this study, men were the highest subjects compared to women, 59 people (77.6\%) compared to 17 people (22.4\%) and had a higher percentage of Syntax than women, 19 people ( $90.5 \%$ ) compared to 2 people $\left(9.5 \%\right.$ ). Based on a population study conducted by Cheng et $\mathrm{al}^{12}$, It was found that men with typical angina had a greater risk factor for coronary heart disease with severe lesions than women ( $19 \%$ versus $11 \%$ with $\mathrm{p}<0.001$ ). The average age of this study is 60 years, according to previous studies with an average age ranging from 50-60 years ${ }^{13}$. At the results of risk factors such as hypertension, diabetes melitus, smoking, BMI, age, and gender, are more common in high Syntax compared to low Syntax, but not statistically significant. Risk factors for dyslipidemia are different and meaningful to Syntax ( $\mathrm{p}<0.05$ ). This is consistent with data from the Framingham study and other cohort studies which show that there is a risk of ischemic heart disease in dyslipidemia in the form of an increase in total cholesterol. Coronary risk occurs as much as 2 times as in someone with a cholesterol level of $240 \mathrm{mg} / \mathrm{gL}$ compared to someone with a cholesterol level of $200 \mathrm{mg} /$ dL). ${ }^{14}$ From the results of the bivariate analysis the group of subjects with high Syntax had lower DTS mean scores than the low Syntax group, and this was statistically significant. The mean DTS in the high Syntax group was $-18.63 \pm 8.85$ and the low Syntax was $-9.21 \pm 3.41(\mathrm{p}<0.001)$. These results are consistent with previous studies which stated that there was a significant negative correlation between DTS and Syntax $(r=-0.9), p$ $<0.001$ ), where subjects included in the high risk DTS had a higher mean Syntax than DTS moderate risk and low risk

From the DTS diagnostic value based on the ROC curve, the area under the curve is $90.1 \%$ ( $<<0.001$ ) and based on the area under this curve the diagnostic value of DTS is very good ${ }^{8}$. Further analysis is carried out to determine the DTS limit value which has an optimal diagnostic value to predict Syntax values. DTS-13.6 is considered to have optimal diagnostic value because it has a balanced sensitivity and specificity. Based on these basic values, DTS is classified into two groups, DTS $\leq-13.6$ and DTS > -13.6. Calculation of diagnostic values is done based on Chi-squared table and obtained a sensitivity of $90 \%$, sensitivity of $61 \%$, negative predictive value of $91.6 \%$, and positive predictive value of $60 \%$. The results of this study have better sensitivity and specificity than studies conducted by Gunaydin et $\mathrm{al}^{9}$ who assessed the DTS relationship with the severity of coronary artery disease assessed by Syntax and obtained AUC of 0.83 (IK 0.7-0.88) with sensitivity of $74 \%$ and specificity of $73 \%{ }^{4}$ The diagnostic value of DTS sensitivity obtained in this study is also better than the diagnostic value based on study conducted by Tamargo et $\mathrm{al}^{15}$, where high risk DTS (DTS <-11) has a sensitivity of $30.8 \%$, specificity of $90.5 \%$, for detecting coronary lesions severity. However, the assessment of coronary artery lesions in the Tamargo study was based on the number and type of coronary arteries involved, whereas in this study were based on Syntax.

Although the diagnostic value of DTS is generally effective for stratifying patients with stable angina pectoris into the appropriate diagnostic and prognostic categories, the addition of other prognostic covariates such as risk factors for coronary heart disease is expected to increase the accuracy of their predictions.

Further analysis was carried out to assess DTS which has added risk factors for CHD to detect the complexity of coronary artery lesions. DTS with risk factors for CHD is divided into 2 groups, high and low risk. Calculation of the diagnostic value is based on Chi-squared table and obtained a sensitivity of 95\%, specificity of $89 \%$, negative predictive value of $98 \%$, and positive predictive value of $77 \%$. The results of this study support the study hypothesis that the DTS values with risk factors for CHD have good diagnostics to detect the complexity of coronary artery lesions which in this study were defined as coronary lesions that have high Syntax . DTS with risk factors for CHD has better sensiivity and specificity than DTS without the addition of CHD risk factors.

Adding risk factors for CHD to DTS values can help in stratifying stable angina pectoris with a high risk group, that will benefit from revascularization and its clinical application is also easy and can be performed on all health services because the variables used are simple and can be done on all health care systems.

\section{Limitations}

Limitations of this study include the absence of a time limit between the treadmill test and coronary angiography at the time of selection of subjects that can be related to the progression of coronary lesion severity. In addition, the percentage of subjects with low female sex caused a low representation of female sex in this study. This study only assessed the number of CHD risk factors and their relationship with Syntax, but 
did not assess risk factors for CHD as a predictor of Syntax. Prospective studies with larger samples are needed to confirm the efficacy of DTS that has added risk factors for CHD to detect the complexity of coronary artery lesions. The addition of CHD risk factors to DTS values to detect the complexity of coronary artery lesions is very simple and easy to do, so we need system validation

\section{Conclusion}

Among all CHD risk factors in this study, only dyslipidemia was different and statistically significant against Syntax $(\mathrm{p}<0.05)$. DTS which has added risk factors for CHD has a higher sensitivity and specificity, 95\% and $85 \%$ compared to DTS without the addition of CHD risk factors, $90 \%$ and $61 \%$ to detect the complexity of coronary artery lesions

\section{References}

1. Wilder J, Sabatine MS, and Lilly. Ischemic Heart Disease Chapter 6.In: Lilly, Leonard S. Pathophysiology of heart disease: a collaborative project of medical students and faculty. 6th ed. Baltimore: Lippincott Williams \& Wilkins, 2016;134-161.

2. Haris, H., \& Elvrida, D. Angina Pektoris Stabil (APS). In: Kasiman. Nyeri dada dari A sampai Z. Medan.Pustaka Bangsa. 2016;10-40.

3. Lilly, L. S. Pathophysiology of heart disease: a collaborative project of medical students and faculty. 6th ed. Baltimore: Lippincott Williams \& Wilkins, 2012.

4. Tardif, C. J. (2010). Coronary Artery Disease in 2010. European Heart Journal, 12(Suppl C), C2-C10. doi:10.1093/eurheartj/suq014.

5. Gibbons, R. J., Balady, G. J., Bricker, T. J., . ... ACC/AHA 2002 Guideline Update for Exercise Testing. American College of Cardiology Foundation and American Heart Association. 2002.

6. Mark, D. B., Hlatky, M. A., Harrel, F. E., . ... (1987). Exercise Treadmill Score for Predicting Prognosis in Coronary Artery Disease. Annals of Internal Medicine, 106(6), 793-800. doi:10.7326/0003-4819-106-6793.

7. Mohr, F. W., Morice, M.-C., Kappetein, A. P., Feldman, T. E., Ståhle, E., Colombo, A., \& Serruys, P. W. (2013). Coronary Artery Bypass Graft Surgery Versus Percutaneous Coronary Intervention in Patients with Three-Vessel Disease and Left Main Coronary Disease: 5- Years Follow Up of The Randomized, Clinical SYNTAX Trial. Lancet, 381(9867), 629-638. doi:10.1016/S0140-6736(13)60141-5.

8. Acar Z, Korkmaz L, Agac M, et al. (2012). Relationship Between Duke Treadmill Score and Coronary Artery Lesion Complexity. Clinical \&Investigative Medicine, 35, 6.

9. Guynadin, Z. Y., Bektas, O., Gurel, Y. E., . ... (2016). The value of the Duke treadmill score in predicting the presence and severity of coronary artery disease. Kardiologia Polska, 74, 127-134.

10. Perhimpunan Dokter Spesialis Kardiologi Indonesia. Pedoman Uji Latih Jantung: Prosedur dan Interpretasi. Jakarta: PERKI.2016.

11. Dahlan, M. S. Penelitian Diagnostik. Edisi ketiga.Jakarta, Penerbit Salemba Medika;2009.

12. Cheng, V. Y., Berman, D. S., Rozanski, A., Dunning, A. M., Achenbach, S., Al-Mallah, M., . ., \& Min, J. K. (2011). Performance of the Traditional Age, Sex, and Angina Typicality-Based Approach for Estimating Pretest Probability of Angiographically Significant Coronary Artery Disease in Patients Undergoing Coronary Computed Tomographic. Angiography. Circulation, 124(22), 2423-2432. doi:10.1161/CIRCULATIONAHA.111.039255.

13. Mayasari, N. M. E., Arso, I. A., \& Maharani, E. (2016). Nilai Diagnostik Dike Teadmill Score untuk Mendeteksi Keparahan Lesi Arteri Koroner pada Pasien yang Terduga Penyakit Jantung Koroner Stabil. Jurnal Kardiologi Indonesia, 37, 65-74.

14. Shahawy, S., \& Libby, P. Atherosclerotic. In: Lilly, Leonard S. Pathophysiology of heart disease: a collaborative project of medical students and faculty. 6th ed. Baltimore: Lippincott Williams \& Wilkins, 2016;112-133.

15. Tamargo, J. A., Ambrosio, S. M., Tarin, E. R., . . .. (2005). Angiographic Evaluation of High Risk Treadmill Score in Patient with Stable Angina According to Sex, Age, or Use of Drugs with Negative Chronotropic Effect. Revista Espanola de Cardiologia, 59, 448-457. 